\title{
Numerical analysis of heat transfer and friction factor in two-pass channels with variable rib shapes
}

\author{
Arjumand Rasool*, Adnan Qayoum \\ Mechanical Engineering Department, National Institute of Technology Srinagar, J \& K, India
}

Corresponding Author Email: arjumand.beigh@yahoo.co.in

https://doi.org/10.18280/ijht.360106

Received: 17 August 2017

Accepted: 12 January 2018

Keywords:

local heat transfer coefficient, numerical simulation, ribs, turbine blade internal cooling

\begin{abstract}
Present investigation deals with the analysis of heat transfer and friction factor for turbulent flow of air through a two-pass square channel, having ribs of various crosssections. The cases undertaken are numerically investigated by commercial software 'Comsol 5.2a' using Standard $\mathrm{k}-\varepsilon$ model. The emphasis is towards investigating the potential impact of differing the shape of ribs for a comparative roughness pitch (p/e) of 10. Four different test cases were analyzed: square, boot, trapezoidal and house rib designs for the Reynold's number range of 5000-52000. The Nusselt number results obtained were validated by comparing with the experimentally and computationally obtained data from earlier studies under similar conditions. The impact of the Reynold's number on the overall performance of various rib shapes has been also investigated. The increment in average Nusselt number over that of the conventional square rib roughened channel is 1.19 and friction factor gets lowered by a factor of 1.3 as compared to square ribs respectively. The analysis shows that characteristics of heat transfer distribution and fluid flow in between the ribs are significantly influenced due to rib design and the boot-shaped rib design shows better heat transfer and friction factor performance than conventional square ribs, and therefore guarantees an enhanced thermo-hydraulic performance.
\end{abstract}

\section{INTRODUCTION}

Technological advancements in heat transfer process is essentially required for thermal energy systems to solve the global energy problem, which can facilitate enhanced heat transfer rate, compactness, longer life and ultimately to get better performance. Current turbine airfoils must operate at extremely high temperatures $\left(1200-1500^{\circ} \mathrm{C}\right)$ to have higher efficiency to combat the demand for high power output. This temperature is above the allowable material temperature for gas turbine blade components. Therefore, it becomes obligatory to have efficient cooling of turbine blades. Application of rib arrays causes interruption of periodic flow and has been accepted as an extensively used method for heat transfer operations such as cooling of gas turbine blades, heat exchangers, fuel elements of gas cooled reactors and microelectronic systems ventilation equipment. Heat transfer augmentation mechanism by ribs is owing to the flow separation and reattachment. The laminar sub-layer disrupted by rib turbulators instigates recreation of the boundary layer, which therefore leads to enhancement in heat transfer. The interruption of the boundary layer causes turbulence in the near wall regions that leads to the dissipation of heat to the mainstream from the near wall fluid owing to the turbulence mix up. Inevitably, these heat transfer enhancement flow mechanisms also amplify the flow drags to raise Fanning friction factors (f), therefore demands for an effective tradeoff. Previously, several computational and experimental studies have been accomplished for evaluating the thermo-hydraulic performance of the rib roughened channels.
The enhancement of heat transfer and cooling approaches used in gas turbine are discussed in detail by Han et al. [1]. The equation which characterizes the advantage of using rough surface design over the smooth surface design was presented by Webb et al. [2] for the similar flow conditions. From last many years, large number of investigations has been carried out to study various factors: rib shape, size, orientation, arrangement, permeability of the rib and the channel configuration (size and rotation) that have noticeable effect on both heat transfer rate and pressure drop aspects in ribbed channels. Most of the relevant literatures [3-10] are dedicated to the evaluation of heat transfer and pressure drop aspects of ribbed channels having square/rectangular cross section of the ribs. Taslim et al. [11] presented the experimental results of heat transfer and pressure drop characteristics of $90^{\circ}, 45^{\circ}$, discrete angled and V-shaped ribs. $45^{\circ}$ and $\mathrm{V}$-shaped ribs were found to give enhanced heat transfer performance than discrete angle and $90^{\circ}$ ribs. However, the channels with square ribs, shows deterioration of coefficient of heat transfer just behind the rib turbulators and was observed by Liou and Hwang [12], hence, in rib-roughened channels flow structures and local heat transfer coefficient needs more explained information, which will help researchers and designers to improve the cooling strategy. Therefore, some attempts were made by researchers to examine the consequences of varying the shape of ribs, which can enhance the heat transfer and pressure drop performance of energy exchange equipment with lesser pressure penalty. In this regard two different geometries fabricated by filling the corners of rectangular ribs with modeling clay were examined by Han et al. [13]. It was found that the rib shape does not affect Nusselt number at 
higher Reynolds number. Channels with square and rounded ribs at a fixed $(\mathrm{p} / \mathrm{e}=7.2)$ and Reynolds number $(\mathrm{Re})$ in range of 10,000 to 30,000 were examined by Lockett and Collins [14]. The authors observed that the heat transfer distribution of rounded ribs vary with $\mathrm{Re}$ whereas square ribs were found independent of Re with the lowest heat transfer rate at the base of the rear face of rib for both cases. Wang et al. [15] carried out an experiment to determine both coefficient of heat transfer and pressure drop in a square duct with bottom wall roughened with ribs of different cross-sectional shapes (square, trapezoidal ribs with increasing and decreasing heights and equilateral-triangular ribs). Their results revealed that the decreasing rib height trapezoidal ribs gave highest Nusselt number ratios.

An attempt to study channels roughened with rib shapes, square, triangular and semicircular cross sections were studied by Liou and Hwang [16]. The authors found the lowest pressure drop for the semicircular ribbed channel as it leads to the most streamlined flow. Also, the semicircular, triangular and square rib shapes have proportionate thermal performance; however hot spots were found at the rear corners behind the ribs in square ribs. The area-averaged heat transfer coefficient by these rib shapes was found to be 1.9-2.7, 1.6-2.1, and 1.72.2 times that of the no-ribbed channel, respectively. Promvonge and Thianpong [17] performed an experiment to study the heat transfer coefficient of channels having rectangular, isosceles triangular, reverse right-angle triangular and right-angle triangular ribs. They reported that the highest heat transfer performance is shown by right-angle triangular ribs.

Several computational investigations were also conducted by researchers; Liu et al. [18] studied numerically the heat transfer and friction loss aspects of isosceles triangular, rectangular, isosceles trapezoidal and semicircular ribs for which Reynolds number vary from 5000-10,000. The highest heat transfer performance was shown by isosceles triangular rib. Wongcharee et al. [19] numerically studied the heat transfer and friction loss aspects of rectangular channel with several rib designs viz. rectangular, cylindrical, triangular, concave-convex, concave-concave, short concave-long convex and short concave-long concave. It was found that triangular geometry ribs provide highest heat transfer performance. Simulations for sixteen rib geometries were performed by Moon et al. [20]; the authors observed that the best heat transfer performance was shown by new bootshaped rib design with a pressure drop comparable to that of the square rib. It was also found that the rib geometry alters the recirculation zone at the rear of the rib and the quantity of turbulent kinetic energy, which ultimately provides the enhancement of heat transfer performance. Therefore, shape of the rib is among the important factors which determine the rate of heat transfer of rib roughened channels. Shevchuk et al [21] studied the heat transfer and pressure drop characteristics in a channel with different distances between divider wall-totip walls. The authors found close match between their numerical and experimental results, therefore it becomes clear that RANS models can predict fluid flow and heat transfer characteristics in a two-pass channel reasonably.

Proper positioning of the ribs has been also identified as a main factor that plays a fundamental role in modifying the flow structures such as separation of flow, reattachment, redevelopment of boundary layer and recirculation behind the ribs and therefore, alters the heat transfer and pressure loss characteristics $[5,8,9]$. One of the earliest test investigations
[4] has found the most favorable value of $\mathrm{p} / \mathrm{e}$ as 10 for square ribs.

Some recent studies $[22,23]$ were carried out to get general ideas regarding how the ribs add to the enhancement in heat transfer in various segments of the two-pass channel. Authors found that all the rib designs shows different heat transfer enhancement rates in the 1 st pass and 2 nd pass.Therefore, in order to segregate the individual effects of ribs and bend in various sections of the channel, they suggested to normalize the ribbed channels with smooth channel.

Pertinent literature as summarized above show the solid impact of rib shapes on the heat transfer coefficient characteristics between the ribs, friction factor and the hot spot formation. However, the above rib shapes heat transfer performances has been limited to single pass channel only and no investigations have yet been reported in two-pass channels The primary purpose of this study is to identify the best possible ribs shape within the range of parameter under investigation (i.e. Re) for enhancement of heat transfer at reduced pressure penalty, with an aim to help in obviating the possible local hotspots. Based on the heat transfer coefficient and friction factor measurements, the thermal performance factor for all the rib geometries are assessed in the current computation while utilizing the constant pumping power criteria [1].

\section{COMPUTATIONAL DETAILS}

Present computation uses standard K- $\varepsilon$ model to carry out investigation of steady, turbulent three-dimensional flow field and the distribution of heat transfer in a ribbed two-pass channel. The computational analysis is handled by the simulation software COMSOL, version 5.2a. COMSOL uses finite element method for solving the governing equations of heat transfer and fluid flow.

To predict the flow field and temperature distribution accurately, it becomes obligatory to have suitable model of turbulence for simulations. Past studies have shown that $\mathrm{k}-\varepsilon$ model determine appropriately separated flow at the rear of ribs and the characteristics of fluid flow in the bend of twopass channels. It has also been reported that heat transfer and pressure loss results from k- $\varepsilon$ model in two-pass channels, shows close conformity to experimental results [24, 25]. Hence, present investigation selected standard k- $\varepsilon$ model for determining the heat transfer and pressure drop characteristics. A comparison of stream-wise variation of span wise-averaged normalized Nusselt number using the K- $\varepsilon$ models shows the results comparable to the experiment as shown in Fig. 5. Slight deviation occurs among the experimental values and computational results, particularly after the bend and downstream the second pass. However, the data are much closer to the experimental in other sections of the channel.

\subsection{Description of the computational model}

Fig. 1 depicts the domain of computational model used for the simulation. All the dimensions of the geometry are in $\mathrm{mm}$. The present computational study includes all rib geometries, as depicted in Fig. 2. However, only square rib geometry and mesh is presented in Fig. 1 and Fig. 3. All the four tested ribs differ only in geometry keeping the cross-sectional area same. The length $(l)$ of the test section is $1000 \mathrm{~mm}$ and the crosssection is $80 \mathrm{~mm} \times 80 \mathrm{~mm}$, and only the bottom wall is heated 
with a constant temperature of $100^{\circ} \mathrm{C}$ for all the summary of cases studied. Ribs were periodically mounted on bottom heated wall, 5 in each pass. The pitch-to-rib height ratio (p/e) and the blockage ratio $\left(\mathrm{e} / \mathrm{D}_{\mathrm{H}}\right)$ of ribs are 10 and 0.1625 , respectively.

have homogeneity for all the rib cases studied, similar grid size was used for the different ribs. The distance of nearest nodes from the wall $(\mathrm{y}+)$ was maintained to less than 10 in all the computations.

Present simulation employs the parametric segregated solver that makes use of pressure-correction scheme which dissociates energy and momentum equations. SIMPLE algorithm was used to make pressure and velocity coupling. Earlier investigations delineated that RANS models can accurately predict the heat transfer and fluid flow characteristics in a two-pass channel.

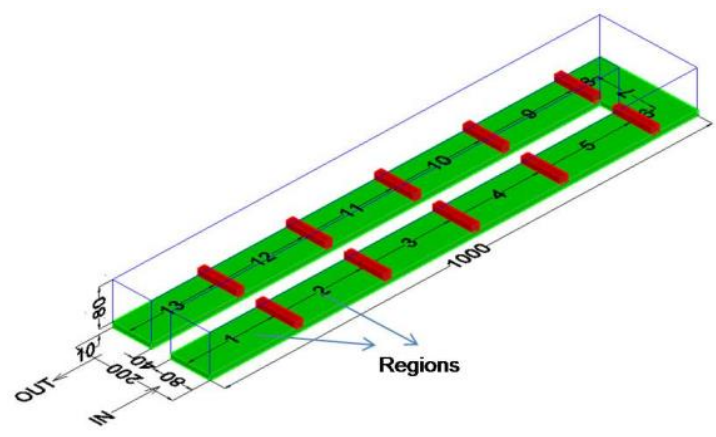

Figure 1. Geometry of a computational domain
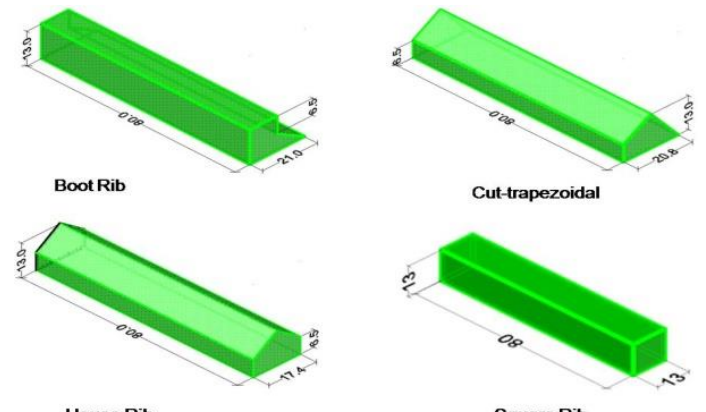

House Rib

Square Rib

Figure 2. Geometry of ribs used in the present investigation

\subsection{Governing equations}

In this study, air is considered to be an incompressible fluid with physical properties being constant, because of small temperature difference along the channel length. The normal governing equations for different variables are expressed below. Since, the present study uses steady Reynolds averaged Navier-stokes (RANS) equations in the air domain and conductive and convective heat equations in the air and the solid wall. The Turbulent non-isothermal flow predefined multiphysics coupling sets up these application modes together with application couplings, making it easy to model Fluid- Thermal interactions.

Continuity equation:

$$
\frac{\partial}{\partial x_{i}}\left(\rho u_{i}\right)=0
$$

Momentum equation:

In the present study a simple linear free triangular mesh was generated in all the regions using COMSOL 5.2a software and Fig. 3 shows the computational grid around the ribs.

In

$\frac{\partial}{\partial x_{i}}\left(u_{i} u_{j}\right)=-\frac{1}{\rho} \frac{\partial p}{\partial x_{j}}+\frac{\partial}{\partial x_{i}}\left[v\left(\frac{\partial u_{i}}{\partial x_{j}}+\frac{\partial u_{j}}{\partial x_{i}}-\frac{2}{3} \delta_{i j} \frac{\partial u_{k}}{\partial x_{k}}\right)\right]$

$+\frac{\partial}{\partial x i}\left(-\overline{u_{i}^{\prime} u_{j}^{\prime}}\right)$

Where,

$-\overline{u_{i}^{\prime} u_{j}^{\prime}}=v_{t}\left(\frac{\partial u_{i}}{\partial x_{j}}+\frac{\partial u_{j}}{\partial x_{i}}\right)-\frac{2}{3} k \delta_{i j}$

$v_{t}=C_{\mu} k^{2} / \varepsilon$

Energy equations:

$$
\begin{aligned}
& \frac{\partial}{\partial x_{i}}\left[u_{i}(\rho E+p)\right]=\frac{\partial}{\partial x_{j}}\left[\left(K+\frac{c_{p} \mu_{T}}{\operatorname{Pr}_{T}}\right) \frac{\partial T}{\partial x_{j}}+u_{i}\left(\tau_{i j}\right) e_{f f}\right] \\
& \left(\tau_{i j}\right)_{e f f}=\mu_{e f f}\left(\frac{\partial u_{i}}{\partial x_{j}}+\frac{\partial u_{j}}{\partial x_{i}}\right)-\frac{2}{3}\left(\mu_{e f f} \frac{\partial u_{k}}{\partial x_{k}}\right) \delta_{i j}
\end{aligned}
$$

\subsection{Boundary conditions}

The incompressible dry air at ambient conditions is selected as working fluid with constant properties. The fluid flow is steady, three-dimensional, non-rotating and turbulent. Inlet temperature is considered to be uniform at $293 \mathrm{~K}$. The value of the inlet fluid velocity was determined by the specific Reynolds number. The turbulence intensity at inlet was fixed at $5 \%$. Also length scale at inlet was specified as $7 \%$ of the hydraulic diameter of channel. Boundary condition (outflow) was imposed at the outlet. A constant temperature of $100^{\circ} \mathrm{C}$ was applied on the ribbed bottom surface. All walls were assumed to be adiabatic and having no-slip impermeable velocity boundary condition.

\section{GRID INDEPENDENCE STUDY}

In order to get assured that the results obtained are independent of the mesh size, a grid independence study was done. Grid independence study was accomplished with square smooth two-pass channel with Reynolds number of 52000 with three distinct grid sizes consists of 200000, 250000 and 330000 elements. The results for stream-wise variation of span-wise averaged normalized Nusselt number obtained by using various grids are compared and shown in Fig.4. The variation in normalized Nusselt number for plane channel among finest and coarsest mesh is $6.3 \%$. Hence, to retain symmetry between computational time economy and efficiency, a grid size consisting of 250000 elements was selected for the present simulation. 


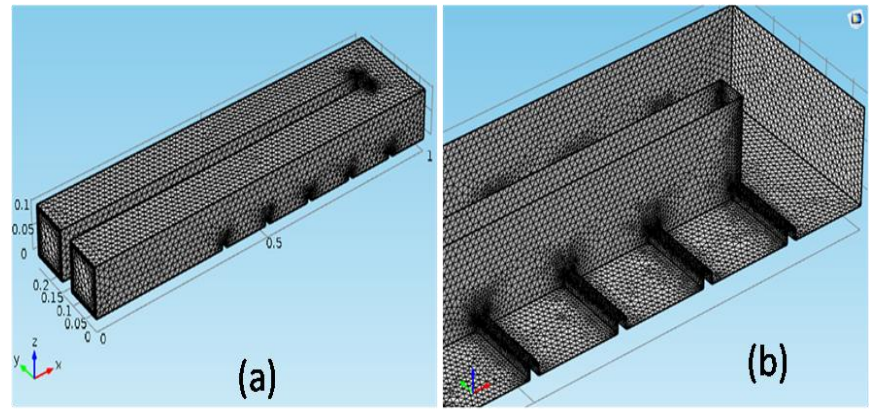

Figure 3. (a) Overall view of the mesh and (b) Mesh Cutsection for square ribs

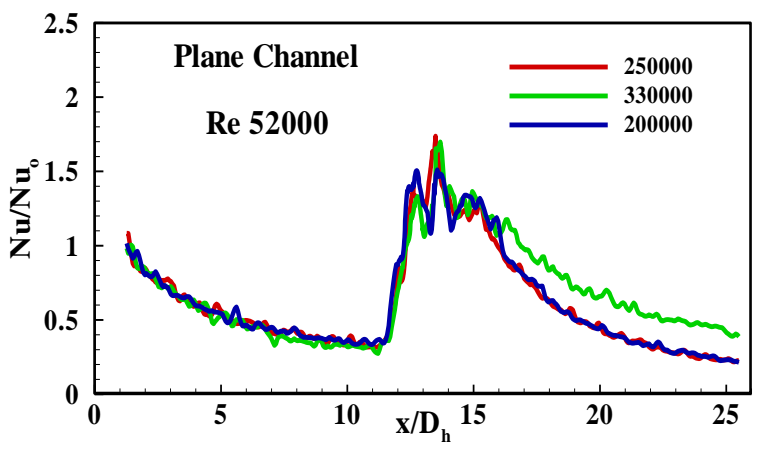

Figure 4. Centerline variation of normalized Nusselt number along Stream-wise direction for three different grids $(\operatorname{Re}=52000)$

\section{DATA REDUCTION}

The coefficient of heat transfer over a ribbed surface is determined as

$$
h=\frac{q^{\prime \prime}}{\left(T_{w}-T_{f}\right)}
$$

where, $\mathrm{q}^{\prime \prime}$ represents heat flux from the constant temperature heated surface to the surrounding bulk fluid. Turbulence variations and fluid velocity are very minute and even vanish very close to the wall. Thermal energy is transported by heat conduction by molecules in the viscous sub-layer region, which prompts the temperature to vary linearly with distance from the wall [26]. Therefore, the heat flux can be evaluated by using temperature gradient as

$$
q^{\prime \prime}=k \frac{\partial T}{\partial n}
$$

Where, $\mathrm{n}$ represents normal to the surface. Therefore, heat transfer coefficient can be evaluated from the temperature of wall, mean fluid temperatures and heat flux. The local mean bulk fluid temperature is a weighted average temperature of fluid and is evaluated at every point in stream-wise direction.

$$
N u=\frac{h D_{H}}{k} \ldots
$$

The Nusselt number obtained from the computation was normalized by the Dittus- Boelter equation for circular tube with smooth walls and turbulent fully developed flow.

$$
N u_{0}=0.023\left(\operatorname{Re}_{o}\right)^{0.8} \operatorname{Pr}^{0.4} \ldots
$$

The Prandtl number (Pr) for the fluid used in the current analysis is 0.71 . Properties of air were calculated at the mean fluid temperature. Friction factor (f) was determined from the Pressure drop $(\Delta \mathrm{P})$ across the test section using Eq. (10).

$$
\begin{gathered}
f=\frac{\Delta P D_{H}}{2 \operatorname{lu}_{\text {avg }}{ }^{2} \rho_{a}} \ldots \\
u_{\text {avg }}=\int_{A} u_{x} d A
\end{gathered}
$$

To normalize the friction factor Blausius equation was used which is given blow

$$
f_{0}=0.316 /\left(\operatorname{Re}_{o}\right)^{0.25}
$$

\subsection{Performance evaluation}

Performance evaluation has been evaluated by taking into account thermal performance against both empirical relations $\left(\eta_{\mathrm{o}}\right)$ and results for smooth channel $\left(\eta_{\mathrm{S}}\right)$ using Eq. (13) and Eq. (14), respectively. This thermal performance index is used to evaluate the amount of pressure loss taking place to raise a certain amount of heat transfer. A higher value of this parameter indicates higher enhancements in heat transfer at small pressure drop. The thermal performance index $(\eta)$ has been calculated under constant pumping power condition. Based on the constant pumping power criteria for the fully developed flow situation Eq. (13) was used to evaluate the thermal performance; however it can be applied for the periodically fully developed region [24]. In the present investigation, when the two pass channel is mounted with array of ribs, the periodicity of the normalized Nusselt number is encountered after 3 to 4 ribs (see Fig. 8). Therefore, thermal performance index $(\eta)$ based on equal pumping power condition has been used to evaluate performance of square, boot, house and cut-trapezoidal ribs.

$$
\begin{gathered}
\eta_{o}=\frac{N u / N u_{o}}{\left(f / f_{o}\right)^{1 / 3}} \ldots \\
\eta_{S}=\frac{N u / N u_{S}}{\left(f / f_{S}\right)^{1 / 3}}
\end{gathered}
$$

\section{COMPUTATIONAL RESULTS}

In the following section, the computational results about time averaged fluid flow and heat transfer analysis are shown in a stationary two pass channel with various rib geometry at specified Reynolds number range. The thermal performance for above rib shapes is also discussed. The Nusselt number 
regulation in first pass, bend and second pass of the two-pass channel are conferred and the rib geometry effects are also presented. At the end, the friction loss was calculated and the results are compared with each other.

\section{$5.1 \quad$ Validation with experiment}

Before initiating the computations for a rib roughened channel, certain validation runs were carried out to find the distribution of Heat transfer coefficient for plane channel. Fig. 5 shows the comparison of current computational results with results of Jang et al. [24], Erelli et al. [27] and Ekkad et al. [28]. The overall trend of the normalized Nusselt number of this study show close agreement with the experimental results excluding close to the start of the second pass which shows lesser value of heat transfer. The possible reason for such behavior could be because of variation in the thickness of divider wall in the present computation than that of Ekkad et al. [28], Jang et al. [24] and Erelli et al. [27]. The variations between the results become prominent behind the turn towards the outlet of the channel because now the flow conditions also depend on the width (thickness) of the divider wall. Also a number of studies $[29,30]$ have revealed that the simple eddy viscosity models are not capable of correctly anticipating the complex turbulent flow physics in the bend and associated regions in the second pass and therefore, gives lesser value of the Nusselt number than the actual. In general the matches between experimental and computational results were found to be satisfactory and therefore it was suggested to carry out with the selected turbulence model.

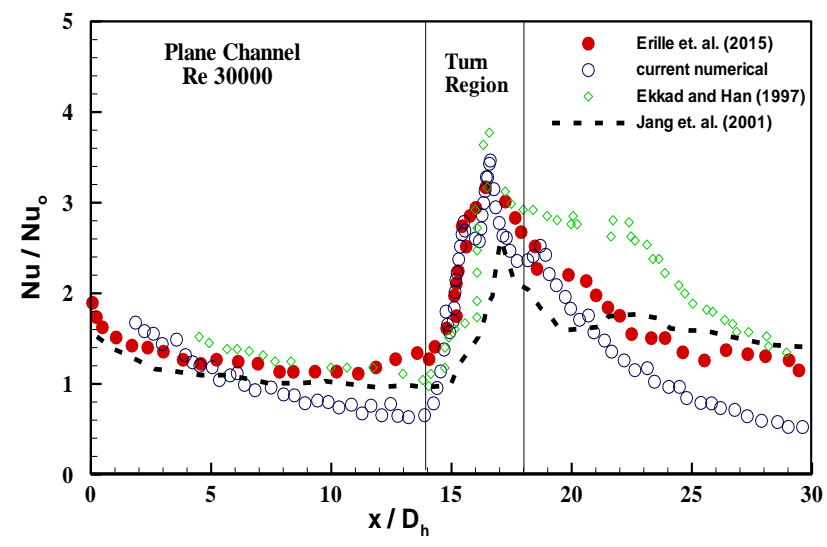

Figure 5. Comparison of normalized Nusselt number with experimental results (Smooth channel $\mathrm{Re}=30,000$ )

Fig. 6 shows the streamline patterns in the inter-rib region, here dead regions (eddy formation) adjoining the ribs both on upstream and downstream-sides can be clearly seen. The downstream side has larger eddies. These are the areas of low heat transfer coefficient. Fig.7 shows the flow reattachment length of the four different rib shapes, the reattachment length of the separated streamline for the boot shaped rib was similar to that of the cut-trapezoidal rib but much shorter than the house shaped rib. House shaped rib was found to produce excessively large separation bubble just behind the rib, the possible reason for this is the upward flow due to the inclined front surface of the house shaped rib. Since, the boot shaped rib induced a flow reattachment earlier than the other shapes, therefore shows the highest heat transfer rate.

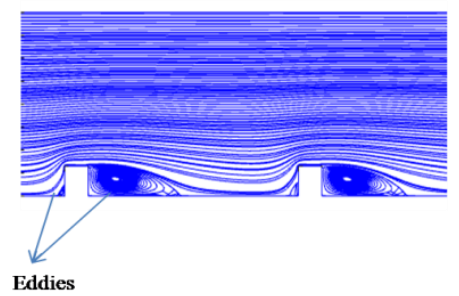

Figure 6. Streamline pattern in the inter-rib region
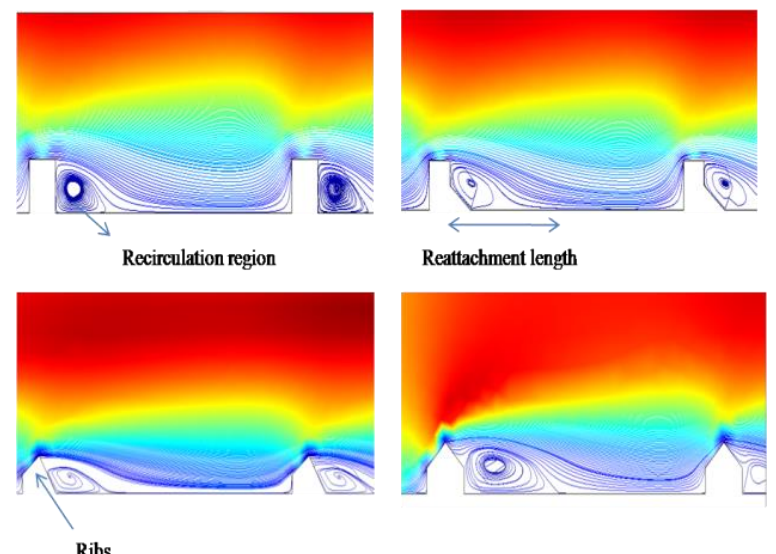

Ribs

Figure 7. Streamlines between third and fourth ribs on $\mathrm{x}-\mathrm{Z}$ plane for ribs

\subsection{Heat transfer characteristics of ribbed channel}

Due to the unavailability of the experimental results for various rib designs, numerical model validation in the present case becomes difficult. In this regard, two important features normalized Nusselt number and friction factor were selected to validate the model. To assess the heat transfer distribution for the current rib shapes, the contours for normalised Nusselt number and the distribution of normalized Nusselt number along the centerline at heated wall connecting two consecutive ribs are presented in Figs. $(8,9)$ at $\mathrm{Re}=10000$ and $\mathrm{P} / \mathrm{e}=10$. The cross-section of the rib shape was found to strongly affect the Nusselt number distribution. The maximum value of Nusselt number was found in front of each rib. Also for each rib shape, there is a sharp decrease in normalized Nusselt number at the rear of the rib. This happens because of separation in flow. The value of normalized Nusselt number slowly increases downstream to achieve its maximum near the line of reattachment. The boot rib design shows the maximum overall heat transfer rate due to the smallest separation zone downstream the rib, the possible reason for that is the geometry of the rear part of the boot-shaped rib. These results led to the conclusion that the reattachment length is a critical function in determining the overall heat transfer rate. Also, Nusselt number ratios in cuttrapezoidal and square ribs are found nearly identical. However,cut-trapezoidal ribs shows additional heat transfer rate than square ribs in the recirculation region just behind the ribs. 


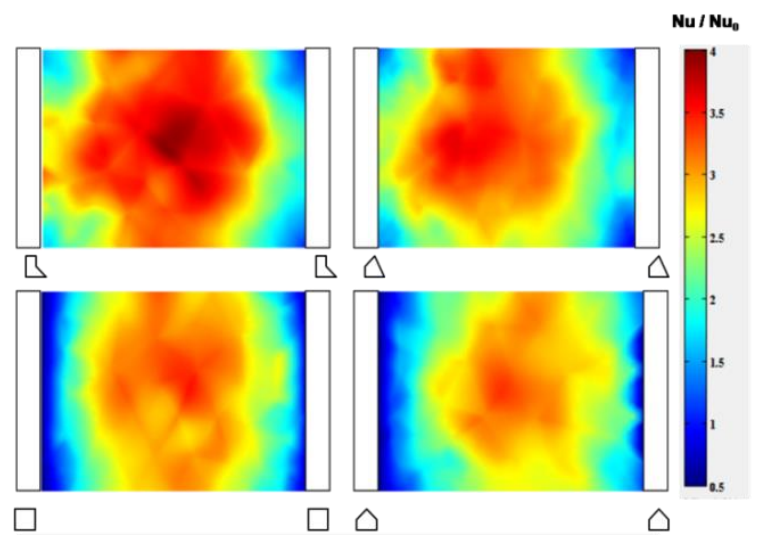

Figure 8. Normalized Nusselt number distributions between two successive ribs

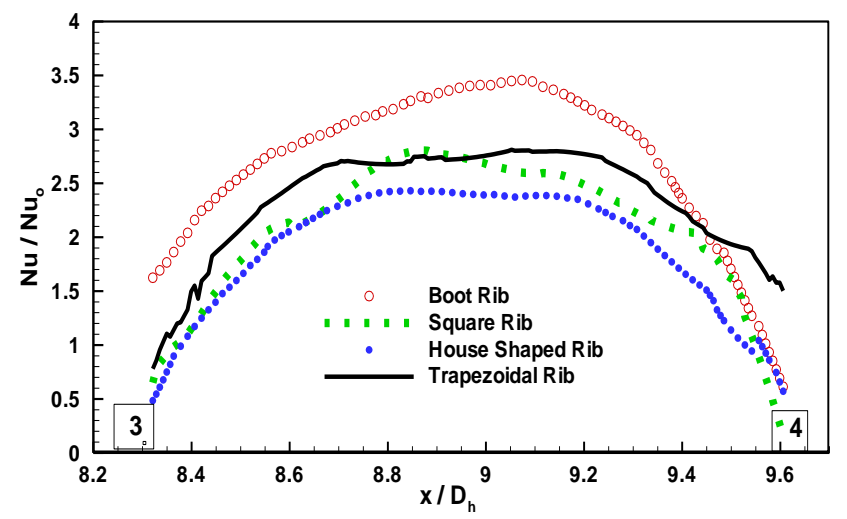

Figure 9. Normalized Nusselt number along the centerline connecting two successive rib at $\mathrm{P} / \mathrm{e}=10$ and $\mathrm{Re}=10,000$

From these results, specific cross-sectional rib shapes, i.e., square, house and boot-shaped rib designs were selected for a comprehensive comparison of the heat transfer and friction factor characteristics. The latter two ribs gave the worst and greatest performance in terms of heat transfer and friction factor respectively, as shown in Fig. 9.

Fig. 10 depicts the distribution of normalised nusselt number contours on the bottom heated surface of the channel with various rib shapes. It can be observed that along the rib, the heat transfer enhancement deteriorates due to the development of boundary layer. Region in between the ribs shows higher heat transfer rate and very low heat transfer rate is found immediately before and after the ribs. Also high heat transfer regions are obtained towards the turn and second pass because of the flow impingement. Further, downstream in the second pass the nusselt number decreases with the reduction in the effect of the turn going down towards the outlet.

Fig.11 shows the comparison of local $\mathrm{Nu} / \mathrm{Nu}_{\mathrm{o}}$ for all rib shapes at $\mathrm{p} / \mathrm{e}=10$ and $\mathrm{Re}=10000$. It is found that the boot shaped rib shows superior heat transfer augmentation for the range of Reynolds's number considered, whereas house shaped ribs shows the lowest heat transfer rate. Therefore, to have a quantitative analysis on the behavior of local heat transfer coefficient distribution, it is essential to estimate the span-wise and region-wise averaged augmentation Nusselt number.

\subsection{Regionally averaged heat transfer characteristics}

For comparison purposes Fig.12 depicts the variation of region-wise averaged normalised Nusselt number distribution $\left(\mathrm{Nu} / \mathrm{Nu}_{\mathrm{o}}\right)$ against the ratio of distance along the $\mathrm{x}$-axis starting from the beginning of the first pass to the hydraulic diameter of the channel $\left(\mathrm{x} / \mathrm{D}_{\mathrm{h}}\right)$ for the rib shapes under consideration. It is also observed from figure that bend region (region 7) shows highest value of heat transfer coefficient for all the ribs studied here. Boot rib shows the highest enhancement in heat transfer in the bend region in contrast to square and house rib designs for all the Reynolds number range studied and $\mathrm{p} / \mathrm{e} 10$.

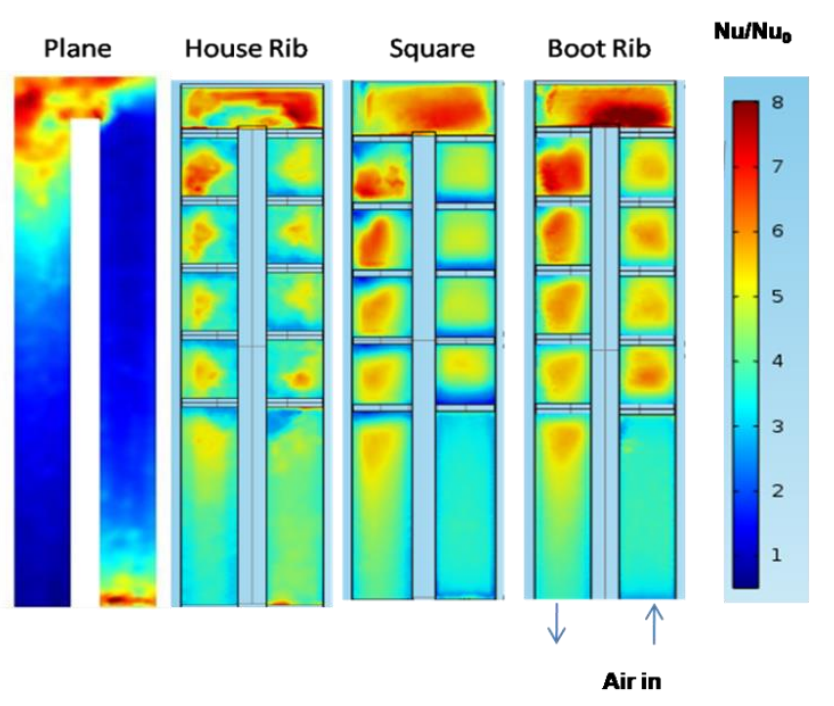

Figure 10. Nusselt number normalized with Dittus-Boelter correlation

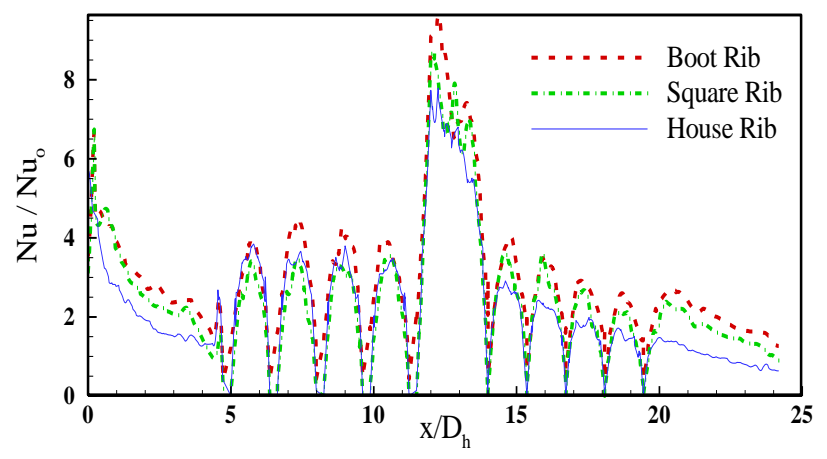

Figure 11. Comparison of local normalized Nusselt number for square, boot and house shaped ribs at Re 10000

In order to get general ideas regarding how the ribs add to the enhancement in heat transfer in various segments of the channel; Fig. 13 represents the average normalized Nusselt number augmentation for all rib shapes considered with respect to plane channel and correlation in the 1st pass, bend and 2 nd pass. As can be seen from the plots, the patterns of the plots ( $\mathrm{Nu} / \mathrm{Nuo}$ and $\mathrm{Nu} / \mathrm{Nus})$ are entirely contrasting. It can be seen from plot $\mathrm{Nu} / \mathrm{Nus}$ that all the rib designs shows higher heat transfer enhancement in the 1st pass than that of the 2nd pass. In the 2nd pass, the attributes of heat transfer and fluid flow are influenced considerably by the ribs generated horseshoe vortices and the Dean-type vortices in turn region. When these two types of vortices interacts with each other they give rise to a complex flow structure which further leads 
to the enhancement of heat transfer coefficient in the 2 nd pass. Therefore, in the 1st pass the contribution of ribs for enhancing the heat transfer rate is higher because there they are completely involved in the process. Thus, it shows the importance of normalizing the ribbed channels with smooth channel, in order to segregate the individual contribution of bend and ribs. Boot ribbed channel shows the maximum enhancement in heat transfer in comparison to smooth channel, whereas house ribbed channel leads to the minimum enhancement. Boot ribs shows 13\% higher value of Nusselt number in the 1st pass, $36 \%$ enhancement in bend region and $28 \%$ enhancement in the 2 nd pass as compared to houseshaped ribs.
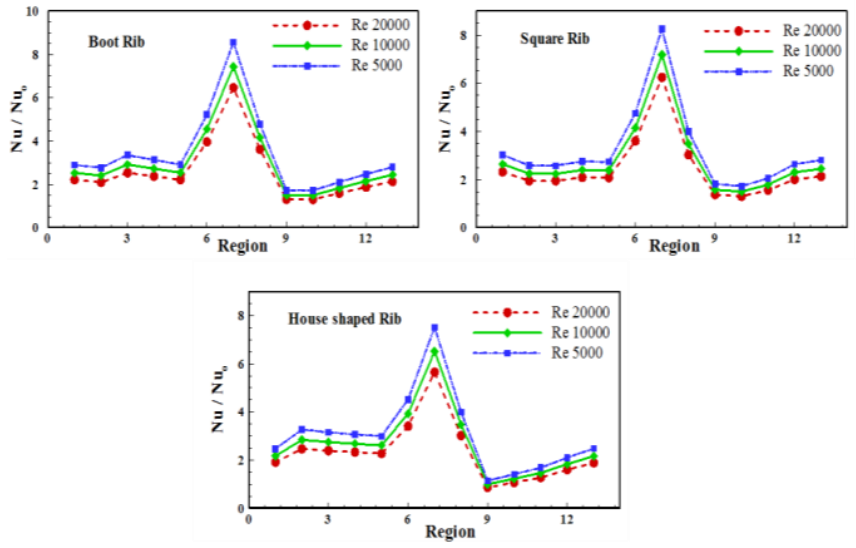

Figure 12. Region-wise averaged normalized Nusselt number
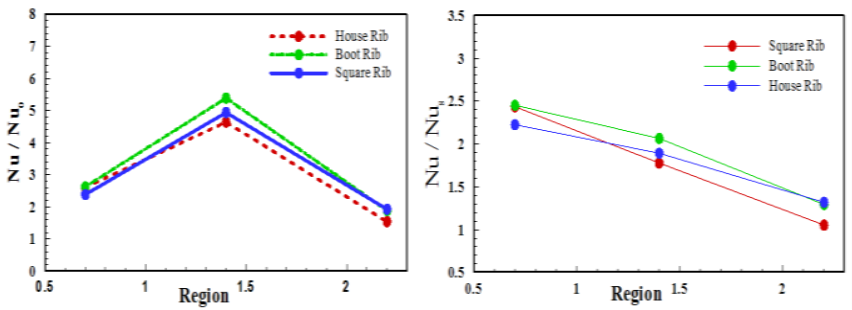

Figure13. Nusselt number enhancement of the two-pass channel at $\operatorname{Re} 20000$

\subsubsection{Overall thermal performance factor comparison}

In order to calculate the thermal performance factor of various rib shapes, overall augmentation Nusselt number $\left(\overline{N u} / \overline{N u}_{o}\right)$ and $\left(\overline{N u} / \overline{N u}_{s}\right)$ against the correlations and smooth channel respectively is studied and presented at different Reynolds number in Fig. 14. In general all the rib configurations offer significant improvement in Nusselt number i, e $\left(\overline{N u} / \overline{N u}_{o}\right)$ and $\left(\overline{N u} / \overline{N u}_{s}\right)>1$ for all the Reynolds number considered. Fig. 14 clearly shows that boot ribs provide higher value of $(\overline{\mathrm{Nu}} / \overline{\mathrm{Nu}} \mathrm{o})$ and $\left(\overline{\mathrm{Nu}} / \overline{\mathrm{Nu}}{ }_{s}\right)$ than square and house ribs. The boot-rib design presents $13 \%$ and $10 \%$ increase in heat transfer enhancement than house and square- rib design respectively. The largest value of normalized Nusselt number is observed at lowest Reynolds number. The heat transfer enhancement decreases with increase in Re for all rib shapes.

The relative friction factor augmentation normalized with reference friction factors (correlation and plane channel) for the various rib shapes is shown in Fig. 15. Friction factor calculation based on pressure drop data was taken by calculating pressure drop at beginning of 1st region and the end of the 13th region. The friction factor augmentation $\left(f / f_{o}\right)$ was found to increase with the increase in Reynolds number. In two-pass channel, the bend is responsible for increasing the overall pressure drop. Therefore, it again becomes important to normalize the ribbed two-pass channel results with that of plane channels. Square ribs shows $11 \%$ and $13 \%$ higher pressure penalty than house and boot rib designs respectively.

The thermal performance factor for the various rib shapes is computed and the results are compared in Fig. 16. The analysis confirmed that the trend of $\left(\overline{N u} / \overline{N u}_{o}\right) /\left(f / f_{o}\right)^{1 / 3}$ is similar to $\left(\overline{\mathrm{Nu}} / \overline{\mathrm{Nu}}_{o}\right)$ and quantifies the pronounced effect of variation of rib shape at different Re. The best thermalhydraulic performance offered by boot-shaped amongst the rib-shapes studied. The thermal performance factor of boot rib design was $36 \%$ higher than the house ribs. The performance in case of square and house-shaped ribs was approximately equal with less than $13 \%$ difference.
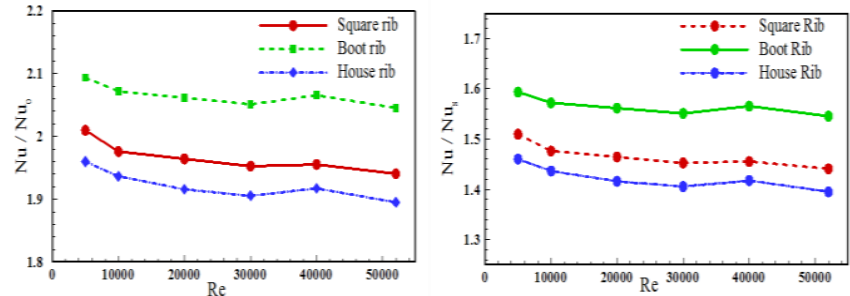

Figure 14. Overall Nusselt number enhancement comparison
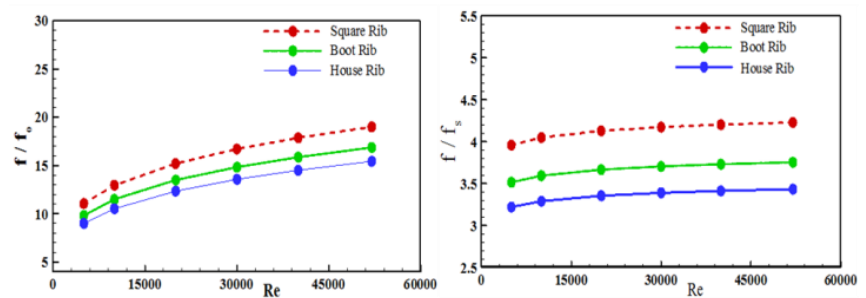

Figure 15. Normalized friction factor comparison
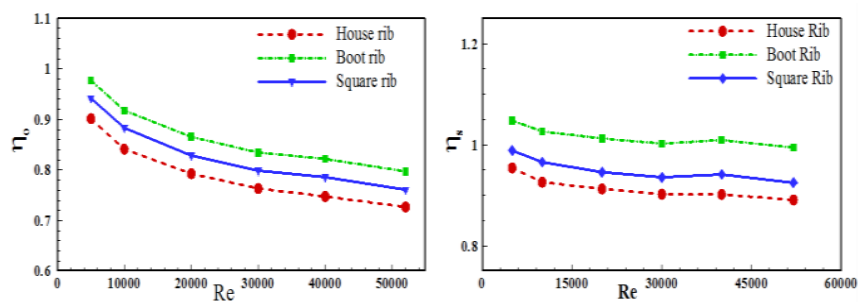

Figure 16. Comparison of thermal hydraulic performance

\section{CONCLUSION}

1. The main conclusion retrieved from above computational study is that a RANS based equations with appropriate turbulence model has the ability to calculate important aspects associated to the heat transfer and fluid flow over the ribbed surface. 
2. The results obtained from the simulations present good qualitative conformity to the experimental studies. However, in the beginning of the second pass heat transfer enhancement was under predicted which shows the significance of accurately modeling the divider wall conditions.

3. The distribution of Nusselt number and friction factor over ribbed surfaces were found to emphatically rely upon the cross-sectional rib shapes.

4. For the Reynolds number under consideration, the best heat transfer performance was given by the boot-shaped rib with a pressure loss performance lower than that of the square rib, and the best pressure loss performance was given by houseshaped rib.

5. The highest performance in terms of heat transfer is shown by the rib designs having vertical front wall (boot shape) while inclined front surface ribs shows the worst performance, with the largest re-circulating regions just behind the rib. Consequently, the front surface of the rib establishes a powerful impact on the extent of the re-circulating zone.

6. Reattachment length plays a very important role in determining heat transfer rate, shorter the reattachment length higher is the heat transfer rate.

7. Heat transfer coefficient generally improves with the increase in Reynolds number.

\section{REFERENCES}

[1] Han JC, Dutta S, Ekkad SV. (2000). Gas turbine heat transfer and cooling technology. CRC Press, New York, Taylor and Francis Group, 287-355.

[2] Webb RL, Eckert ERG. (1972). Application of rough surfaces to heat exchanger design. Int. J. of Heat Mass Transfer 15(9): 1647-1658. https://doi.org/10.1016/0017-9310(72)90095-6

[3] Acharya S, Dutta S, Myrum TA, Baker RS. (1993). Periodically developed flow and heat transfer in a ribbed duct. Int. J. of Heat and Mass Transfer 36(8): 2069-2082. https://doi.org/10.1016/S0017-9310(05) 80138-3

[4] Han JC, Park JS. (1988). Developing heat transfer in rectangular channels with rib turbulators. Int. J. of Heat and Mass Transfer 31(1): 183-195. https://doi.org/10.1016/0017-9310(88)90235-9

[5] Rau G, Cakan M, Moeller D, Arts T. (1998). The Effect of periodic ribs on the local aerodynamic and heat transfer performance of a straight cooling channel. ASME J. of Turbomachinery 120(2): 368-375. https://doi. org/ 10.1115/1.2841415

[6] Aliaga DA, Lamb JP, Klein DE. (1994). Convection heat transfer distributions over plates with square ribs from infrared thermography measurements. Int. J. of Heat and Mass Transfer 37(3): 363-374. https://doi.org/10.1016/0017-9310(94)90071-X

[7] Tanda G. (2011). Effect of rib spacing on heat transfer and friction in a rectangular channel with $45^{\circ}$ angled rib turbulators on one/two walls. Int. J. of Heat and Mass Transfer 54(54): 1081-1090. http://dx.doi.org/10.1016/j.ijheatmasstransfer.2010.11. 015

[8] Chandra PR, Alexander CR, Han JC. (2003). Heat transfer and friction behaviors in rectangular channels with varying number of ribbed walls. Int. J. of Heat and Mass Transfer 46(3): 481-495. https://doi.org/10.1016/S0017-9310(02)00297-1

[9] Tariq A, Panigrahi PK, Muralidhar K. (2004). Flow and heat transfer in the wake of a surface mounted rib with a slit. Experiments in Fluids 37(5): 701-719. https://doi.org/ 10.1007/s00348-004-0861-8

[10] Hwang JJ. (1998). Heat transfer- friction characteristic comparison in rectangular ducts with slit and solid ribs mounted on one wall. ASME J. of Heat Transfer 120(3): 709-716. https://doi.org/ 10.1115/ 1.2824340

[11] Taslim ME, Li T, Kercher DM. (1996). Experimental heat transfer and friction in channels roughened with angled, V-shaped and discrete ribs on two opposite walls. Journal Turbomach 4: 20-8. https://doi.org/ 10.1115/94-GT-163

[12] Liou TM, Hwang JJ. (1992). Turbulent heat transfer augmentation and friction in periodic fully developed channel flows. ASME J.of Heat Transfer 114(1): 5664. https://doi.org/ 10.1115/1.2911267

[13] Han JC, Glicksman LR, Rohsenow WM. (1978). An investigation of Heat Transfer and Friction for Rib Roughened Surfaces. Int J. of Heat and Mass Transfer 21(8): 1143-1156. https://doi.org/10.1016/00179310(78)90113-8

[14] Lockett JF, Collins MW. (1990). Holographic interferometry applied to rib-roughness heat transfer in turbulent flow. Int. J. of Heat and Mass Transfer 33(11): 2439-2449. https://doi.org/ 10.1016/00179310(90)90002-C

[15] Wang L, Sunden B. (2007). Experimental investigation of local heat transfer in a square duct with various-shaped ribs. Int. J. of Heat Mass Transfer 18(3): 759-766. https://doi.org/10.1080/ 08916150590953397

[16] Liou TM, Hwang JJ. (1993). Effect of ridge shapes on turbulent heat transfer and friction in rectangular channel. Int. J. Heat Mass Transfer 36(4): 931-940. https://doi.org/10.1016/S0017-9310(05)80277-7

[17] Promvonge P, Thianpong C. (2008). Thermal performance assessment of turbulent channel flows over different shaped ribs. Int. Commun. Heat Mass Transfer 35(10): 1327-1334. https://doi.org/10.1016/ j.icheatmasstransfer.2008.07.016

[18] Liu P, Gao HM, Liu H. (2010). Numerical simulation of heat transfer and resistance pattern in channels with different ribs. Int. Conf. Comput. Des. https://doi.org/ $10.1109 / 2010.5541336$

[19] Wongcharee K, Changcharoen W, Eiamsa-ard S. (2011). Numerical investigation of flow friction and heat transfer in a channel with various shaped ribs mounted on two opposite ribbed walls. Int. J. of Chem. Reactor Eng 9(1). https://doi.org/10.1515/15426580.2560

[20] Moon MA, Park MJ, Kim KY. (2014). Evaluation of heat transfer performances of various rib shapes. Int. J. of Heat and Mass Transfer 71. https://doi.org/10.1016/j.ijheatmasstransfer.2013.12.02 6

[21] Shevchuk IV, Jenkins SC, Weigand B, Wolfersdorf JV. (2011). Validation and analysis of numerical results for a varying aspect ratio two-pass internal cooling channel. J. of Heat Transfer 133(5): 051701-051708. https://doi.org/ 10.1115/1.4003080 
[22] Ravi BV, Ekkad SV, Singh P. (2017). Numerical investigation of turbulent flow and heat transfer in two-pass ribbed channels. Int. J. of Thermal Sciences 112: 31-43. https://doi.org/10.1016/ j. ijthermalsci. 2016.09.034

[23] Singh P, Ravi BV, Ekkad SV. (2016). Experimental and numerical study of heat transfer due to developing flow in a two-pass rib roughened square duct. Int. J. Heat Mass Transfer 102: 1245-56 https://doi.org/10.1016/j.ijheatmasstransfer.2016.07.01 5

[24] Jang YJ, Chen HC, Han JC. (2001). Computation of flow and heat transfer in two pass channels with 60 deg ribs. J. Heat Transfer 123(3): 563-575. https://doi.org/ 10.1115/1.1371931

[25] Saha K, Acharya S. (2013). Effect of bend geometry on heat transfer and pressure drop in a two-pass coolant square channel for a turbine. J. Turbomach 135(2) 763-71. https://doi.org/10.1115/1.4006665

[26] Han S, Goldstein RJ. (2008). The heat/mass transfer analogy for a simulated turbine blade. Int. J. of heat and mass transfer 51: 5209-5225. https://doi.org/10.1016/j.ijheatmasstransfer.2008.04.00 2

[27] Erelli R, Saha K, Panigrahi PK. (2015). Influence of turn geometry on turbulent fluid flow and heat transfer in a stationary two-pass square duct. Int. J. of Heat and Mass $\quad$ Transfer 89: 667-684 https://doi.org/10.1016/j.ijheatmasstransfer.2015.05.08 1

[28] Ekkad SV, Han JC. (1997). Detailed heat and mass transfer distribution in a two-pass Square channel with rib turbulators. Int. J. of Heat and Mass Transfer 40(11): 2525-2537. https://doi.org/10.1016/S00179310(96)00318-3

[29] Ooi A, Iaccarino G, Durbin PA, Behnia M. (2002) Reynolds averaged simulation of flow and heat transfer in ribbed ducts. Int. J. Heat and Fluid Flow 23(6): 750-757. https://doi.org/10.1016/ S0142727X(02)00188-1
[30] Sleiti AK, Kapat JS. (2006). Comparison between EVM and RSM turbulence models in predicting flow and heat transfer in rib roughened channels. J Turbulence 7: 531-542. https://doi.org/ 10.1080/ 14685240500499343

\section{NOMENCLATURE}

$\begin{array}{ll}\mathrm{D}_{\mathrm{H}} & \text { Hydraulic diameter }[\mathrm{m}] \\ \mathrm{e} & \text { Rib height }[\mathrm{m}] \\ \mathrm{f} & \text { Friction factor } \\ \mathrm{h} & \text { Heat transfer coefficient }\left[\mathrm{W} / \mathrm{m}^{2} \mathrm{~K}\right] \\ \mathrm{k} & \text { Thermal conductivity }[\mathrm{W} / \mathrm{mK}] \\ l & \text { Channel length }[\mathrm{m}] \\ \mathrm{Nu} & \text { Nusselt number } \\ \overline{\mathrm{Nu}} \quad \text { Globally averaged Nusselt number } \\ \mathrm{channel} \\ \mathrm{p} & \text { Rib pitch }[\mathrm{m}] \\ \mathrm{P} & \text { Pressure }[\mathrm{Pa}] \\ \mathrm{q} & \text { Heat flux }\left[\mathrm{W} / \mathrm{m}^{2}\right] \\ \mathrm{Re} & \text { Reynolds number }\left[\rho \mathrm{u}_{\text {in }} \mathrm{D}_{\mathrm{h}} / \mu\right] \\ \mathrm{T} & \text { Temperature }[\mathrm{K}] \\ \mathrm{u} & \text { Fluid velocity }[\mathrm{m} / \mathrm{s}]\end{array}$

\section{Subscripts}

0 From Dittus-Boelter Coorelation

$S$ Smooth surface

f Fluid

w wall

in inlet

\section{Greek symbols}

pa Density of air $[\mathrm{kg} / \mathrm{m} 3]$

$\eta \quad$ Thermo-hydraulic performance

$\mu \quad$ Dynamic viscosity

$[\mathrm{kg} / \mathrm{ms}]$ 